\title{
The vertical accuracy of digital terrain models derived from the close-range photogrammetry point cloud using different methods of interpolation and resolutions
}

\author{
Juraj Čerňava ${ }^{1, *}$, František Chudý1, Daniel Tunák ${ }^{1}, \check{S ̆ i m o n ~ S a l o n ̌}^{1}$, Zuzana Vyhnáliková ${ }^{2}$ \\ ${ }^{1}$ Technical University in Zvolen, Faculty of Forestry, T. G. Masaryka 24, SK-960 01 Zvolen, Slovak Republic \\ ${ }^{2}$ Technical University in Zvolen, Institute of Foreign Languages, T. G. Masaryka 24, SK - 96001 Zvolen, Slovak Republic
}

\begin{abstract}
Structure-from-motion (SfM) in combination with multi-view stereo (MVS) represent techniques, which allow efficient generation of the point cloud from close-range photogrammetry (CRP) images of forest ground. Recent software products for the generation of digital terrain models (DTM) includes a wide range of interpolation methods. Previous studies showed different errors in elevations of DTMs interpolated with different methods. This study aims to analyze differences between the elevations of DTMs derived from CRP point cloud using different methods of interpolation. Six methods of interpolation included in modular system OPALS were tested in the study. In addition to simple methods of interpolation such as Snap or Moving average, more complex methods were used for interpolation of the DTMs elevations. For each method, 5 DTMs with resolution ranging from 1 to $20 \mathrm{~cm}$ were generated. Elevations of the DTMs were compared with the elevations of Global Navigation Satellite System (GNSS) surveyed check points. RMSE of DTMs elevations ranges from $3.4 \mathrm{~cm}$ to $16.2 \mathrm{~cm}$. Differences between the elevations of DTMs interpolated using different methods and resolution were further investigated using one-way analysis of variance (ANOVA). The ANOVA rejected the statistical significance of the differences. Additionally, the spatial distribution of errors was analyzed. The analysis indicates that the interpolation of the extreme DTM values can be expected at the edges of the DTM when using the CRP images captured from single passing through the study site.
\end{abstract}

Key words: close-range photogrammetry; digital terrain model; OPALS; structure-from-motion; multi-view stereo

Editor: Vladimír Šebeň

\section{Introduction}

Monitoring of forest ground is very important, especially during the harvest. The monitoring can help prevent the negative impact of soil erosion on the forest. The impact of soil disturbances on the forest was demonstrated in many studies (Jacobsen \& Greacen 1985; Heninger et al. 2002; Modrý et al. 2003; Bassett et al. 2005; Schäffer et al. 2012; Gebauer et al. 2012; Cambi et al. 2016). The disturbances affect mainly the root growth, which consequently decreases the forest regeneration (Heninger et al. 2002; Modrý et al. 2003; Bassett et al. 2005; Gebauer et al. 2012; Cambi et al. 2016). Moreover, the disturbed soil can also decrease water quality (Christopher \& Visser 2008). Generally, the studies confirm the significance of the forest ground monitoring as a tool for avoiding further degeneration of forest growth and water quality (Christopher \& Visser 2008; Schäffer et al. 2012; Affek et al. 2017).
Close-range photogrammetry (CRP) has already shown its potential to provide very detailed and accurate digital terrain model (DTM) (Zapp \& Nearing 2005; Gessesse et al. 2010; Westoby et al. 2012; Liu \& Huang 2016; Hrůza et al. 2018; Chudý et al. 2019). According to Pierzchała et al. (2015), the advantage of photogrammetry-based methods using modern compact cameras is that they can be used handheld or mounted on forest machines or low-cost drones, while laser scanners remain comparatively heavy and costly. Furthermore, using a handheld camera for image acquisition is the easiest and cheapest way to capture the state of the forest at a particular moment in time. DTM derived from CRP images taken from a close distance can dispose of sub-centimeter vertical accuracy (Zapp \& Nearing 2005; Gessesse et al. 2010). However, these models are limited only for an experiment with area up to a few tens of square meters. Digital terrain models with larger areas dispose of lower accuracy and are usually derived from

*Corresponding author.Juraj Čerňava, e-mail:juraj.cernava@tuzvo.sk 
CRP images acquired in a kinematic manner (Hrůza et al. 2018; Chudý et al. 2019).

Structure-from-motion (SfM) and multi-view stereo (MVS) methods are used for the generation of the point cloud from CRP data. DTM can be derived using only the SfM-MVS software (Pierzchała et al. 2015; Goetz et al. 2018). DTM can also be derived from a point cloud generated by SfM-MVS software using additional software (Haas et al. 2016; Mölg \& Bolch 2017). The vertical accuracy of DTM derived from CRP point cloud is influenced by multiple factors. The image matching precision can mainly be affected by choosing the optimal software for the point cloud generation. Some differences in vertical accuracy of DTM and quality of point cloud generated by different software were shown (Niederheiser et al. 2016; Mölg \& Bolch 2017).

Evaluation of DEMs for skid trail erosion assessment was discussed in previous studies (Haas et al. 2016; Pierzchała et al. 2016). Quality of the digital elevation model (DEM) was assessed using yardstick measurements taken along the skid trail in Haas et al. (2016). DEM validation can be also carried out by manual measurements of skid trail profile as it was demonstrated in Pierzchała et al. (2016). However, in most of the studies, the vertical accuracy of DEM is assessed using the GNSS and total station surveyed check points (Arun 2013; Liu \& Huang 2016; Goetz et al. 2018; Tomaštík et al. 2019). Laser scanning derived DEM can also be used as reference data for DEM vertical accuracy assessment (Westoby et al. 2012; Gašparović et al. 2017). The continuous data are very beneficial for the detection of bias of tested DEM.

Influence of interpolation method on the DTM quality has been investigated in previous studies (Robinson \& Metternicht 2006; Arun 2013; Akar 2017). The method can influence DTM with lower resolution commonly derived from satellite imagery (Robinson \& Metternicht 2006; Arun 2013). Differences between the high-resolution DTMs derived from UAV imagery interpolated using multiple methods has shown to be not significant (Akar 2017). Comparison of some studies also shows how much is the vertical accuracy of DTM influenced by its resolution (Robinson \& Metternicht 2006; Arun 2013; Akar 2017).

Although the CRP point cloud usually disposes of high point density, factors such as DTM resolution and method of the DTM interpolation should be investigated. Latest software for DTM generation provides a wide range of interpolation methods (Robinson \& Metternicht 2006; Mandlburger et al. 2009; Arun 2013). This study aims to analyze the vertical accuracy of DTM derived from CRP point clouds with respect to DTM resolution and interpolation method. Additionally, the study aims to analyze the spatial distribution of DTM errors to further reveal the cause of extreme value interpolation.

\section{Materials and methods}

\subsection{Study site}

This study was conducted for the skid trail located within the forest in Budča, near Zvolen in the Slovak Republic (Fig. 1). Study site covers approx. $1022 \mathrm{~m}^{2}$ of forest road and neighboring areas. The forest is managed by Forest enterprise of Technical University in Zvolen - Budča. Study site lies in the area with southeastern aspect and average slope of $35 \%$.

Forest surrounding the study site began to be harvested a few months before the data acquisition. Studied skid trail begins at the logged part of forest stand and connects the forest with a highway. It directs from northwest to southeast. Harvesting was carried out in the southeastern part of the study area, which is situated at lower elevations compared to the skid trail. Studied part of the skid trail was not affected by the recent harvest.

\subsection{Close-range photogrammetry survey}

CRP images from 70 meters of the skid trail and surrounding areas were acquired. Data acquisition was done in late November 2017. Canon EOS 5D Mark II camera mounted on a pole was used for the image acqui-

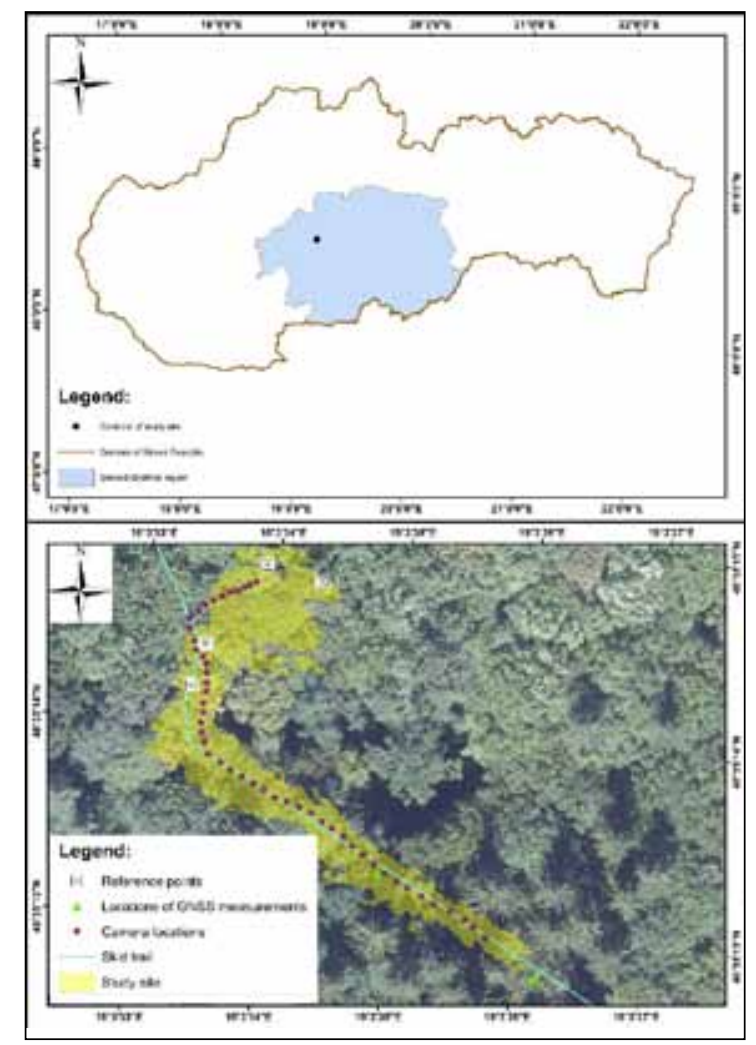

Fig. 1. Location of study site within the borders of Slovakia is shown in the upper figure. Locations of the camera during the CRP surveys, locations of static GNSS measurements and locations of reference points used for point cloud georeferencing are shown in the lower figure. 
Table 1. Camera specification.

\begin{tabular}{lcccc}
\hline Camera & Resolution & Focal Length $[\mathrm{mm}]$ & Pixel Size $[\mu \mathrm{m}]$ & Precalibrated \\
\hline Canon EOS 5D Mark II & $5616 \times 3744$ & 35 & $6.55 \times 6.55$ & No \\
\hline
\end{tabular}

sition (Table 1 ). The camera was located $2.5 \mathrm{~m}$ above the ground during the acquisition. Eighty-eight images of forest ground were acquired with a shutter speed of $1 / 80 \mathrm{~s}$, the $\mathrm{f}$-number of $\mathrm{f} / 6.3$ and ISO of 400 . In the first survey, 48 images were acquired with 4 reference points. In the second survey, 40 images were acquired with 5 reference points. The images were acquired by moving the camera along the centerline of the skid trail. Positions of the camera during the CRP surveys are shown in Fig. 1.

\subsection{Static Global Navigation Satellite System and total station survey}

Check points within the study area were surveyed using a total station and two static GNSS measurements (Fig. 1). The points were firstly surveyed by the total station and telescopic prism pole with a bubble. Tip of the pole was placed on the ground surface without inserting the pole into the soil. Locations of the 145 check points were measured. The points were surveyed from only one position of the total station. Coordinates of the points measured by the total station were transformed to S-JTSK coordinate system using two static GNSS measurements with 10 min duration. The static measurements were located at the edge of the recently harvested area (Fig. 1). Locations of GNSS measurements were checked using the total station. Distance from one point measured using GNSS to another was compared to the distance measured using the total station. If the difference between the distance measurements was higher than $2 \mathrm{~cm}$, the GNSS measurement was carried out again.

The precision of static GNSS measurements was assessed by Slovak real-time positioning service (SKPOS). Horizontal precision was $0.4 \mathrm{~cm}$ and vertical precision was $0.6 \mathrm{~cm}$ for the point located inside the study site (Fig. 1). Horizontal precision was $0.8 \mathrm{~cm}$ and vertical precision was $1.4 \mathrm{~cm}$ for a point located outside the study site.

\subsection{Close-range photogrammetry point cloud generation}

CRP images were aligned and georeferenced in Agisoft's PhotoScan (Agisoft LLC 2016). Images alignment was set to the highest accuracy and pair selection was disabled. Images were aligned using 310,345 tie points for the first survey. Images from the second survey were aligned using 162,796 tie points. Point clouds were georeferenced using 4 and 5 control points. The precision of the georeferencing was calculated in PhotoScan based solely on the control points. For the first and second survey, the point cloud was georeferenced with XY RMSE of 0.22 $\mathrm{cm}$ and Z RMSE of $0.06 \mathrm{~cm}, \mathrm{XY}$ RMSE of $0.9 \mathrm{~cm}$ and $\mathrm{Z}$ RMSE of $0.24 \mathrm{~cm}$, respectively. This precision was considered as sufficient for the generation of DTM. Point clouds from 2 surveys were merged and new point cloud consisted of $65,402,845$ points.

\subsection{Ground points classification}

Software suite - LAStools (Isenburg 2016) was used for classification of ground points. LAStools classifies the ground points using the triangulated irregular network (TIN). Four parameters are necessary for the classification. First, the size of the step used for classification was set to $1 \mathrm{~m}$. Maximal bulging of the TIN was set to $1 \mathrm{~m}$. Points located $0.3 \mathrm{~m}$ above the coarsest TIN were defined as the up-spikes and removed. Points located more than $3 \mathrm{~m}$ below the TIN were defined as down-spikes and removed. Points up to $5 \mathrm{~cm}$ above the TIN based ground were classified as the ground points. Finally, ground points were exported as a new point cloud with a density of 334 points $/ \mathrm{m}^{2}$. The point cloud was then used during the following processing.

\subsection{Generation of digital terrain models}

Ground points extracted from CRP point clouds were used for DTM generation. DTMs were generated in OPALS, version 2.3.0 (Mandlburger et al. 2009; Otepka et al. 2012; Pfeifer et al. 2014). The OPALS module Grid offers eight methods of grid interpolation as well as five methods of DTM gaps filling. Six methods of the interpolation (Snap, Delaunay triangulation, Moving average, Moving paraboloid, Moving planes, Robust Moving planes) were tested in this study.

In addition to simple methods of interpolation such as Snap or Moving average, more complex methods were used for interpolation of the DTMs. Delaunay triangulation uses the TIN for grid interpolation. To avoid data gaps for an interpolated grid cell, additional points from neighboring cells are considered within a distance of 3 times the grid cell size. The methods based on the moving plane (Moving planes, Robust Moving planes) use the plane tilted so it best fits the points within the DTM cell to interpolate the cell value. For each grid cell, 8 nearest points are queried and a best-fitting tilted plane is estimated (by minimizing the vertical distances) (OPALS Team 2016). The height of the resulting plane at the grid point $(\mathrm{x}, \mathrm{y})$ position is mapped to the grid cell. The tilted plane interpolator allows the derivation of slope measures ( $\mathrm{x}$-component of the surface normal unit vector, $\mathrm{y}-$ component of the surface normal unit vector, slope, exposition) for each grid point. Moving paraboloid searches 
for the paraboloid (2nd order polynomial) that best fits the points located within the cell of DTM to interpolate its value. The height of the resulting paraboloid at the grid point $(\mathrm{x}, \mathrm{y}$,$) position is mapped to the grid cell (OPALS$ Team 2016). The paraboloid interpolator allows the derivation of curvature measures (minimum curvature, minimum curvature, mean curvature, Gaussian curvature) for each grid point. The more complex methods of interpolation can interpolate more accurate DTMs in certain cases. To test the methods for DTM generation from a very dense CRP point cloud, we compare the DTMs with the DTMs interpolated using simple methods such as Snap, for which the detail and accuracy are much more dependent on the quality of the source data.

For each method of interpolation, DTMs with resolution (grid cell size) ranging from $1 \mathrm{~cm}$ to $20 \mathrm{~cm}$, with an interval of $5 \mathrm{~cm}$ were generated from a set of ground points. Apart from the DTM resolution and method of interpolation, all remaining parameters used for the generation of DTM were set to default.

In the next processing step, gap-filling module was used to generate compact DTMs without the gaps. The gaps are represented by pixels with NoData value within the DTM extent. Adaptive method of gap filling was used for processing of all the DTMs. The method uses adaptive plane fit with inverse distance weighting to interpolate missing values of the DTM grid cells. Boundary ratio was set to 1 , so only gaps fully surrounded by data were filled.

Statistical significance of differences between reference elevations (static GNSS measurement) and elevation interpolated using all methods of interpolation was determined by one-way Analysis of Variance (ANOVA).

DTMs were validated in respect of vertical accuracy using check points from static GNSS and total station survey. Root mean square error (RMSE) and mean error (ME) were calculated for each DTM as it is defined in [2] and [3].

$$
\begin{aligned}
& e=Z_{D T M}-Z_{D G N S S} \\
& M E=\frac{\sum_{i=1}^{n}(e)}{n}
\end{aligned}
$$

$$
Z_{N D V I}=\frac{N D V I-\overline{N D V I}}{\sigma_{N D V I}}
$$

where $z_{D G N S S}$ is z coordinate of the check point measured by the GNSS and total station combination and $z_{D T M}$ is the value of DTM cell, which center is the nearest to the check point. The possible bias of DTM interpolation was further investigated for DTMs with $1 \mathrm{~cm}$ resolution using the t-test.

For further analysis of the DTM, the spatial distribution of DTM elevation errors was investigated. Mean errors were calculated using errors of DTMs [Eq. 1] with the highest resolution $(1 \mathrm{~cm})$. Errors of DTM interpolated by Moving paraboloid were excluded from the calculation of the mean errors. These errors have significantly influenced the mean value because some extreme values were interpolated using this method.

\section{Results}

\subsection{Digital Terrain Models}

Overall, 30 DTMs were generated. For 145 regularly distributed check points, the elevation ranges from 359.88 to $366.14 \mathrm{~m}$ (Fig. 2). It can be seen that the mean elevation of DTMs with the resolution of $1 \mathrm{~cm}$ is slightly overestimated for all the DTMs (cross mark in Fig. 2). Furthermore, elevation ranges and standard deviation are shifted towards the higher values for all the DTMs. This indicates that the elevation values are positively biased. Besides this, the elevation values interpolated using different methods of interpolation are very similar. One-wayANOVAalso rejected the statistical significance of elevation differences among the methods of interpolation and reference with a $\mathrm{p}$-value of 1 for the DTMs with the resolution of $1 \mathrm{~cm}$. The same result of ANOVA was achieved for DTMs with the resolution of $20 \mathrm{~cm}$.

Root mean square error (RMSE) and mean error (ME) were used to validate each DTM in respect of vertical accuracy. Accuracies of the DTMs were assessed using 145 check points. For DTMs interpolated using

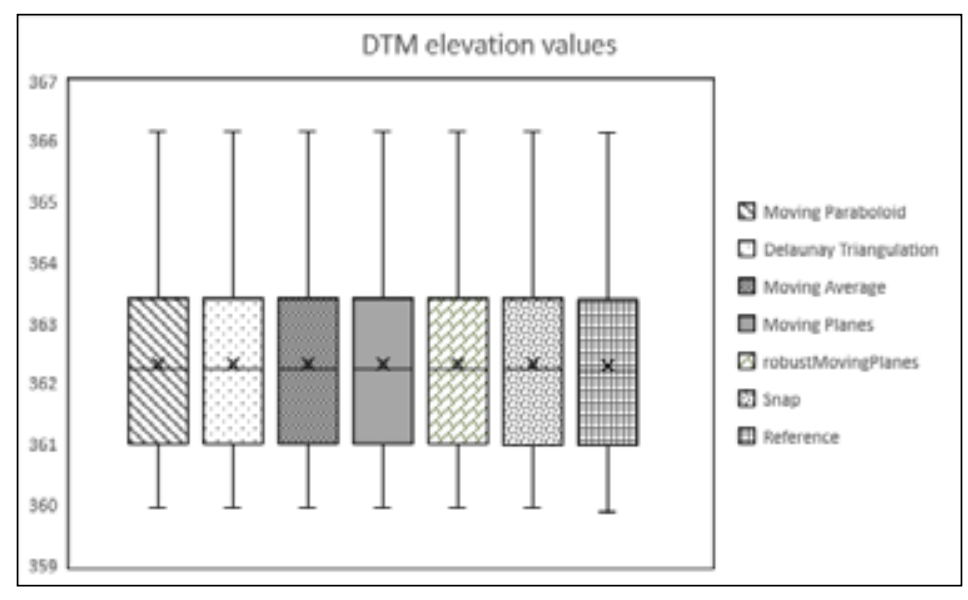

Fig. 2. Box plots of DTM elevation values for all DTM with a resolution of $1 \mathrm{~cm}$. 
Robust moving planes and Moving planes methods, the number of check points varied between 143 and 145. The variability was caused by the different extent of DTMs with different resolutions.

For all the DTMs, mean errors were calculated. The errors show that elevations in the DTMs are overestimated with ME ranging from $1.19 \mathrm{~cm}$ to $2.39 \mathrm{~cm}$ (Table $2)$. The t-test rejected bias of the DTM elevations with very low $\mathrm{p}$-values ranging from $1.51 \times 10^{-18}$ to $9.33 \times 10^{-6}$ (Table 2). Therefore, the slight positive bias visible on Fig. 2 is rejected.

RMSE was calculated for all DTMs. The error ranges from $3.4 \mathrm{~cm}$ to $16.2 \mathrm{~cm}$. Highest RMSE was calculated for DTMs interpolated using Moving paraboloid method. Except for the DTMs interpolated using Moving paraboloid, the RMSE ranges only from $3.4 \mathrm{~cm}$ to $3.9 \mathrm{~cm}$ (Table 2). This result shows the small influence of method of DTM interpolation and DTM resolution on the vertical accuracy of DTM derived from CRP point cloud.

Furthermore, the spatial distribution of the errors was investigated. For 5 methods of interpolation (Moving Paraboloid excluded), the mean errors range from $-5 \mathrm{~cm}$ to $8.79 \mathrm{~cm}$ (Fig. 3). Most of the errors are ranging from
$3 \mathrm{~cm}$ to $4 \mathrm{~cm}$ (Fig. 3). Highest DTM errors are located at the edge of the DTM extent or in the areas with a higher occurrence of gaps derived from parts of the point cloud with lower point density (Fig. 4). The absolute difference between the lowest and highest errors is $8.78 \mathrm{~cm}$. Most of the sub-centimeter errors are located near to the trajectory of images acquisition, in the areas with a low occurrence of gaps.

\section{Discussion}

Thirty different DTMs were interpolated from CRP point cloud of forest ground. The sample of elevations measured by static GNSS has a range of approx. $6 \mathrm{~m}$. Statistical significance of differences interpolated using 6 different methods was rejected by one-way ANOVA. This was revealed for both $1 \mathrm{~cm}$ and $20 \mathrm{~cm}$ DTMs. Therefore, ANOVA rejected statistical significance also for the differences in elevation between the DTMs with different resolutions. Despite this, DTM vertical accuracy varies slightly. For all the DTM, positive mean error in elevation was calculated. In previous studies, the DTM elevations tended to be also underestimated (Hrůza et al. 2018).

Table 2. Mean errors and root mean square errors in DTM elevation for different methods of interpolation and DTM resolutions. Presented p-values for different methods of interpolation were calculated using t-test.

\begin{tabular}{|c|c|c|c|c|c|c|}
\hline \multicolumn{7}{|c|}{ Method of interpolation } \\
\hline & Delaunay triangulation & Moving average & Moving planes & Moving paraboloid & Robust moving planes & Snap \\
\hline DTM resolution $[\mathrm{cm}]$ & \multicolumn{6}{|c|}{ Root mean square error $[\mathrm{cm}]$} \\
\hline 1 & 3.51 & 3.49 & 3.53 & 7.40 & 3.52 & 3.59 \\
\hline 5 & 3.58 & 3.59 & 3.50 & 12.15 & 3.50 & 3.61 \\
\hline 10 & 3.66 & 3.65 & 3.60 & 10.69 & 3.60 & 3.43 \\
\hline 15 & 3.79 & 3.90 & 3.78 & 10.41 & 3.78 & 3.40 \\
\hline 20 & 3.74 & 3.66 & 3.72 & 16.20 & 3.72 & 3.58 \\
\hline DTM resolution $[\mathrm{cm}]$ & \multicolumn{6}{|c|}{ Mean error $[\mathrm{cm}]$} \\
\hline 1 & 2.21 & 2.25 & 2.65 & 2.27 & 2.27 & 2.22 \\
\hline 5 & 2.30 & 2.32 & 1.58 & 2.26 & 2.27 & 1.95 \\
\hline 10 & 2.39 & 2.38 & 1.42 & 2.35 & 2.35 & 1.89 \\
\hline 15 & 2.29 & 2.32 & 1.80 & 2.28 & 2.27 & 1.33 \\
\hline 20 & 2.31 & 2.28 & 1.76 & 2.22 & 2.22 & 1.19 \\
\hline p-value & $1.94 \times 10^{-17}$ & $1.84 \times 10^{-18}$ & $9.33 \times 10^{-6}$ & $2.41 \times 10^{-18}$ & $1.51 \times 10^{-18}$ & $9.84 \times 10^{-}$ \\
\hline
\end{tabular}

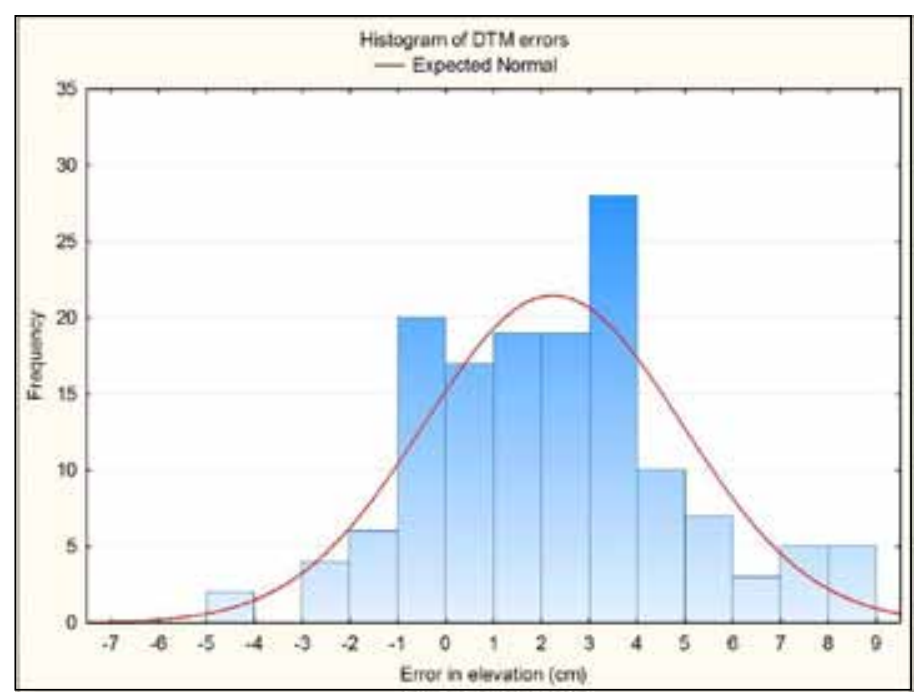

Fig. 3. Distribution of DTM errors. The errors were calculated as mean of errors of the DTMs with $1 \mathrm{~cm}$ resolution except for the DTM interpolated using Moving paraboloid method. 


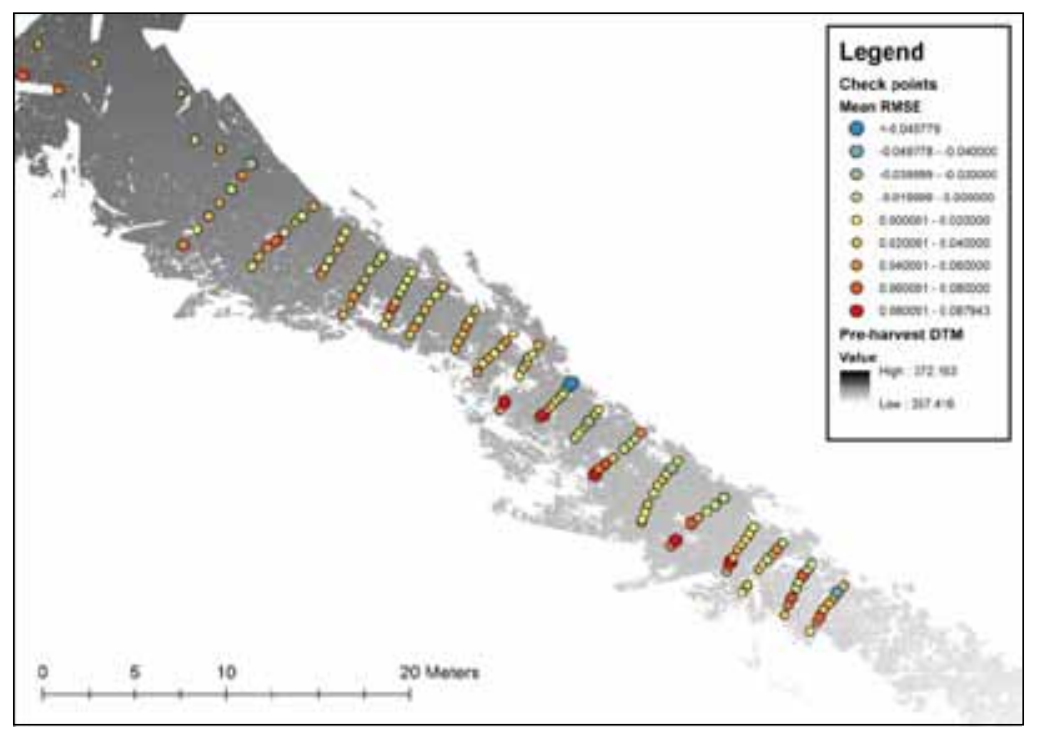

Fig. 4. Spatial distribution of errors with DTM in the background. The DTM with a resolution of $1 \mathrm{~cm}$ without filled gaps is shown in the figure.

The overestimation of elevations was reported for DTM derived from CRP images acquired statically (Gessesse et al. 2010). The overestimation is usually observed for DTM derived from airborne laser scanning data of forest ground (Reuterbuch et al. 2003; Sačkov \& Kardoš 2014; Hrůza et al. 2018). Furthermore, the DTMs with overestimated elevations was reported for UAV-based photogrammetry point cloud (Goetz et al. 2018). Overall, the most accurate DTMs were interpolated using Snap method, which represents the simplest of all presented methods. Generally, the RMSE of DTM slightly varies around $3.5 \mathrm{~cm}$, if we do not consider erroneous DTMs interpolated using Moving paraboloid method. DTMs with RMSE ranging from 1 to several meters are usually derived from satellite imagery (Arun 2013; Alganci et al. 2018). The errors of DTM derived from satellite imagery vary greatly also based on the land cover (Alganci et al. 2018). Lower accuracy can also be expected for DTMs derived from UAV imagery (Akar 2017; Goetz et al. 2018). The RMSE of DTMs derived from UAV imagery can reach approx. $5 \mathrm{~cm}$ (Goetz et al. 2018; Tomaštík et al. 2019). Very detailed DTMs can reach vertical accuracy up to several millimeters (Zapp \& Nearing 2005; Gessesse et al. 2010). DEM with accuracy higher than the proposed DTMs can be derived from a point cloud generated from monochromatic images (Zapp \& Nearing 2005). The standard error of elevation differences of $1.26 \mathrm{~mm}$ was reported by Zapp \& Nearing (2005) for the experimental flume with dimensions of $4 \times 4 \times 0.8 \mathrm{~m}^{3}$. The similar standard error of $\pm 5.6 \mathrm{~mm}$ was reported for DEM derived from CRP images of freshly tilled bare soil surface with plot size of $53 \mathrm{~m}^{2}$ (Gessesse et al. 2010). Studies reporting very low standard errors were conducted for the study site with a small area and the CRP images were acquired in a static manner (Zapp \& Nearing 2005; Gessesse et al. 2010). However, the studies show the highest verti- cal accuracy of DTM that can be achieved for the CRP data. Very promising accuracy $(\mathrm{RMSE}=1.1 \mathrm{~cm}$ ) was achieved also by Hrůza et al. (2018) for DTM from CRP point cloud of asphalt paved forest road. The CRP images were recorded from a car at the higher speed. On the other hand, the very smooth surface of the road causes an increase in vertical accuracy of the DTM.

Method of DTM interpolation influences the DTM vertical accuracy and the interpolated values can differ for surface models derived from airborne or satellite imagery (Arun 2013, Akar 2017, Alganci et al. 2018). For satellite imagery, the differences in interpolated values can reach several meters (Arun 2013). The differences in RMSE of DTMs interpolated using different methods can reach tens of centimeters even for photogrammetry point cloud from UAV (Akar 2017). Results of this study indicate a small influence of interpolation method on the vertical accuracy of DTM derived from CRP point cloud. Besides the Moving paraboloid method of interpolation, the DTM RMSE varies only a slightly for different methods of interpolation $(0.5 \mathrm{~cm})$. In this study, the DTM with extreme values was interpolated using Moving paraboloid method.

What seems to influence the vertical accuracy of DTM the most is the point cloud density. The spatial distribution of errors, shown in Fig. 4, shows that the highest errors are located either near the edges of the DTM extent or in areas with more gaps. These areas of DTM were interpolated from a smaller number of points. The errors of DTM values interpolated from low-density parts of the CRP point cloud can amount to $9 \mathrm{~cm}$. For parts of the point cloud with a higher density of points, the DTM can be interpolated with an error of several millimeters. Besides the higher DTM error near the edges of DTM extent, for DTM of more complex terrain like mountains or rock glacier, the highest errors can be expected in areas with greatest elevation changes (Goetz et al. 2018). 


\section{Conclusion}

This study showed that the differences in elevation of DTMs interpolated using different methods of interpolation and different resolution of the DTM grid are not statistically significant. Except for the DTMs interpolated using Moving paraboloid, the RMSE ranges from $3.4 \mathrm{~cm}$ to $3.9 \mathrm{~cm}$. Methods of interpolation presented in the study represent a wide range of approaches to the interpolation of DTM. Therefore, similar results can be expected for DTMs derived from CRP point cloud from forest ground interpolated using the method, which was not directly presented in the study. From the methods of interpolation presented in the study, we do not recommend the use of methods such as Moving paraboloid for interpolation of DTM from very dense CRP point cloud from the forest ground. Dozens of extreme values were interpolated using this method. Excluding the DTMs generated using Moving paraboloid, the mean RMSE decreases from 4.91 $\mathrm{cm}$ to $3.62 \mathrm{~cm}$.

Spatial distribution of errors shows that the density of point cloud used for DTM generation can influence the vertical accuracy of DTM. Furthermore, the analysis of the spatial distribution indicates that the interpolation of extreme value can be expected at the edges of the DTM extent, which are located the farthest from the trajectory of image acquisition, especially in the case of using only single crossing through the study site for the acquisition. The density of point cloud is influenced mainly by the acquisition of CRP images and should be investigated in the future.

\section{Acknowledgements}

This study was supported by Science grant agency of the Ministry of Education, Science, Research and Sport of the Slovak Republic and Slovak Academy of Sciences project VEGAMŠ SR and SAV no. 1/0868/18: 'Innovative techniques for mapping anthropogenic and natural forms of terrain and relief applicable in survey of a landscape state'.

\section{References}

Affek, A., Zachwatowicz, M., Sosnowska, A., Gerlée, A., Kiszka, K., 2017: Impacts of modern mechanised skidding on the natural and cultural heritage of the Polish Carpathian Mountains. Forest Ecology and Management, 405:391-403.

Agisoft LLC, 2016: Agisoft Photoscan 1.2.4. build 2336. St. Petersburg. Russia: Agisoft LLC 11 Degtyarniy pereulok.

Akar, A., 2017: Evaluation of vertical accuracy of DEMs obtained from UAV-point cloud for different topographical areas. International Journal of Engineering and Geosciences, 2:110-117.
Alganci, U., Besol, B., Sertel, E., 2018:Vertical accuracy Assessment of Different Digital Surface Models. ISPRS International Journal of Geo-Information, 7, $114 \mathrm{p}$.

Arun, V. P., 2013: A comparative analysis of different DEM interpolation methods. The Egyptian Journal of Remote Sensing and Space Sciences, 16:133-139.

Bassett, I. E., Simcock, R. C., Mitchell, N. D., 2005: Consequences of soil compaction for seedling establishment: implications for natural regeneration and restoration. Austral Ecology, 30:827-833.

Cambi, M., Hoshika, Y., Mariotti, B., Paoletti, E., Picchio, R., Rachele, R. et al., 2016: Compaction by a forest machine affects soil quality and Quercus robur L. seedling performance in an experimental field. Forest Ecology and Management, 384:406-414.

Christopher, E. A., Visser, R., 2007: Methodology for evaluating post-harvest erosion risk for the protection of water quality. New Zealand Journal of Forestry, 52:20-25.

Chudý, F., Slámová, M., Tomaštík, J., Prokešová, R., Mokroš, M., 2019: Identification of Micro-Scale Landforms of Landslides Using Precise Digital Elevation Models. Geosciences, 9:117.

Eltner, A., Mulsow, C., Maas, H. G., 2013: Quantitative measurement of soil erosion from TLS and UAV data. In: International Archives of the Photogrammetry, UAV-g2013, 4 - 6 September 2013, Rostock, Germany. Remote Sensing and Spatial Information Sciences, XL-1/W2:119-124.

ESRI, 2013: ArcGIS Desktop, Release 10.2. Redlands, CA: Environmental Systems Research Institute.

Gašparović, M., Seletković, A., Berta, A., Balenović, I., 2017: The Evaluation of Photogrammetry-Based DSM from Low-Cost UAV by LiDAR-Based DSM. South-east European Forestry, 8:117-125.

Gebauer, R., Neruda, J., Ulrich, R., Martinková, M., 2012: Soil compaction - impact of harvesters' and forwarders' passages on plant growth, sustainable forest management - Current Research, (Diez J, ed), InTech, 10, p. 179-196. ISBN 978-953-51-0621-0.

Gessesse, D. G., Fuchs, H., Mansberger, R., Klik, A., Rieke-Zapp, H. D., 2010. Assessment of Erosion, Deposition and Rill Development On Irregular Soil Surfaces Using Close Range Digital Photogrammetry. The Photogrammetric Record, 25:299-318.

Goetz, J., Brenning, A., Marcer, M., Bodin, X., 2018: Modeling the precision of structure-from-motion multi-view stereo digital elevation models from repeated close-range aerial surveys. Remote Sensing of Environment, 210:208-215.

Haas, J., Ellhöft, H. K., Schack-Kirchner, H., Lang, F., 2016: Using photogrammetry to assess rutting caused by a forwarder - A comparison of different tires and bogie tracks. In Soil \& Tillage Research, 163:14-20. 
Heninger, R., Scott, W., Dobkowski, A., Miller, R. Anderson, H., Duke, S., 2002: Soil disturbance and 10-year growth response of coast Douglas-fir on nontilled and tilled skid trails in the Oregon Cascades. Canadian Journal of Forest Research, 32:233-246.

Hrůza, P., Mikita, T., Tyagur, N., Krejza, Z., Cibulka, M., Procházková, A. et al., 2018: Detecting Forest Road Wearing Course Damage Using Different Methods of Remote Sensing. Remote Sensing, 10:492.

Isenburg, M., 2016: LAStools - efficient LiDAR processing software, version 160429 (unlicensed), obtained from http://rapidlasso.com/LAStools.

Jakobsen, B. F., Greacen, E. L., 1985: Compaction of sandy forest soils by forwarder operations. Soil and Tillage Research, 5:55-70.

Liu, C. W., Huang, C. W., 2016: Close range digital photogrammetry applied to topography and landslide measurements. The International Archives of the Photogrammetry, Remote Sensing and Spatial Information Sciences, Volume XLI-B5, 2016, XXIII ISPRS Congress, 12-19 July 2016, Prague, Czech Republic.

Mandlburger, G., Otepka, J., Karel, W., Wagner, W., Pfeifer, N., 2009: Orientation and Processing Of Airborne Laser Scanning Data (OPALS) - Concept and first results of a comprehensive ALS software. In: Bretar F., Pierrot-Deseiligny M., Vosselman G. (eds.): The International Archives of the Photogrammetry, Remote Sensing and Spatial Information Sciences, XXXVIII, Part 3/W8. Paris, Sept 1-2, 2009, p. $55-60$.

Modrý, M., Hubený, D., 2003: Impact of skidder and high-lead system logging on forest soils and advanced regeneration. Journal of Forest Science, 49:273-280.

Mölg, N., Bolch, T., 2017: Structure-from-Motion Using Historical Aerial Images to Analyse Changes in Glacier Surface Elevation. Remote Sensing, 9:1021.

Niederheiser, R., Mokroš, M., Lange, J., Petschko, H., Prasicek, G. Elberink, O. S., 2016: Deriving 3D point clouds from terestrial photographs - Comparison of different sensors and software. In: The International Archives of the Photogrammetry, XXIII ISPRS Congress, 12-19 July 2016, Prague, Czech Republic. Remote Sensing and Spatial Information Sciences, 41: 685-692.
Otepka, J., Mandlburger, G., Karel, W., 2012: The OPALS Data Manager - Efficient Data Management for Processing Large Airborne Laser Scanning Projects. ISPRS Annals, Comm. III, 1-3:153-159.

Pfeifer, N., Mandlburger, G., Otepka, J., Karel, W., 2014: OPALS - A framework for Airborne Laser Scanning data analysis. Computers, Environment and Urban Systems, 45:125-136.

Pierzchała, M., Talbot, B., Astrup, R., 2016: Measuring wheel ruts with close-range photogrammetry. Forestry: An International Journal of Forest Research, 89:383-391.

Reutebuch, E. S., McGaughey, J. R., Andersen,H. E., Carson,W. W., 2003: Accuracy of a high-resolution lidar terrain model under a conifer forest canopy, Canadian Journal of Remote Sensing, 29:527-535.

Rieke-Zapp, D. H., Nearing, M. A., 2005: Digital close range photogrammetry for measurement of soil erosion. The Photogrammetric Record, 20:69-87.

Robinson, T. P., Metternicht, G., 2006: Testing the performance of spatial interpolation techniques for mapping soil properties. Computers and Electronics in Agriculture, 50:97-108.

Sačkov, I., Kardoš, M., 2014: Forest delineation based on LiDAR data and vertical accuracy of the terrain model in forest and non-forest area. Annals of Forest Research, 57:119-136.

Schäffer, J., Buberl, H., Von Wilpert, K., 2012: Deformation damages in forest topsoils-An assessment based on Level-I soil monitoring data from Baden- Württemberg (SW Germany). Journal of Plant Nutrition and Soil Science, 175:24-33.

Tomaštík, J., Mokroš, M., Surový, P., Grznárová, A., Merganič, J., 2019: UAV RTK/PPK Method-An Optimal Solution for Mapping Inaccessible Forested Areas? Remote Sensing, 11:721.

Westoby, M. J., Brasington, J., Glasser, N. F., Hambrey, M. J., Reynolds, J. M., 2012:'Structure-from-Motion' photogrammetry: Alow-cost, effective tool for geoscience applications. Geomorphology, 179:300-314. 